\title{
Selenium supplementation restores the decreased albumin level of peripheral blood mononuclear cells in streptozotocin-induced diabetic mice
}

\author{
Taeho AHN ${ }^{1) *}$, Chun-Sik BAE ${ }^{1)}$ and Chul-Ho YUN ${ }^{2)}$ \\ ${ }^{1)}$ College of Veterinary Medicine, Chonnam National University, Gwangju 500-757, Republic of Korea \\ ${ }^{2)}$ School of Biological Sciences and Technology, Chonnam National University, Gwangju 500-757, Republic of Korea
}

(Received 27 October 2015/Accepted 19 December 2015/Published online in J-STAGE 3 January 2016)

ABSTRACT. Previously, it has been suggested that the phenotypic level of albumin in peripheral blood mononuclear cells (PBMC) decreased in streptozotocin (STZ)-induced diabetic rats. Concomitantly, the production of oxidative stresses was also elevated in the diabetic PBMC compared to that of normal control. These results suggest the close relationship between PBMC-albumin and its antioxidant roles. Here, we expanded the previous studies and investigated the effect of selenium supplementation as inorganic (sodium selenate) forms on the levels of albumin expression and oxidative stress in PBMC of STZ-induced diabetic mice. Selenium intake recovered the decreased albumin levels to those of normal mice and reduced the production of reactive oxygen species (ROS). These results support that selenium intake may alleviate the etiology and pathology of PBMC in type 1 diabetic mice by restoring the decrease in albumin contents and the production of ROS. KEY WORDS: albumin, diabetes, oxidative stress, selenium, streptozotocin

doi: 10.1292/jvms.15-0611; J. Vet. Med. Sci. 78(4): 669-674, 2016

Oxidative stress has been implicated in the etiology and pathogenesis of chronic complications associated with diabetes $[1,24]$. Streptozotocin (STZ) has been widely used to induce type 1 diabetes mellitus (DM) and other concomitant disorders in animal models. Hyperglycemia, auto-oxidation of glycated proteins and increased production of reactive oxygen species (ROS) were reported in STZ-treated rats, resulting in increased oxidative stress that is accompanied by pancreatic $\beta$-cell damage $[4,7]$. STZ has also been shown to deplete the antioxidant pool in cells, making them more susceptible to oxidative damage [9].

Serum albumin has a number of important physiological and pharmacological functions including maintaining vascular permeability [16] and transport of various molecules. Antioxidant activity is one of the most prominent functions of albumin [2, 21]. Therefore, decreased level of albumin may act as a contributing factor to the development of various oxidative stress-related diseases including diabetes and even cancer. In addition to oxidative stress, decreased level of serum albumin per se is another complication of diabetes due to its decisive role in regulating osmotic pressure of plasma. Low hepatic synthesis of albumin has also been suggested as another factor for the decrease in albumin level in diabetes [14].

Albumin is mainly synthesized in the liver, representing about $25 \%$ of total hepatic proteins. In addition to the liver, non-hepatic transcription of albumin has been reported in

*Correspondence to: Ahn, T., College of Veterinary Medicine, Chonnam National University, Gwangju 500-757, Republic of Korea.

e-mail: thahn@chonnam.ac.kr

C2016 The Japanese Society of Veterinary Science

This is an open-access article distributed under the terms of the Creative Commons Attribution Non-Commercial No Derivatives (by-nc-nd) License $<$ http://creativecommons.org/licenses/by-nc-nd/4.0/>. several tissues, such as the kidney, pancreas, intestine and lymph gland [10, 22]. Moreover, lymphocytes also have membrane-bound albumin, although its physiological functions including the origin remain unclear [23].

Peripheral blood mononuclear cells (PBMC) are the population of blood cells having a round nucleus, such as lymphocytes, monocytes and macrophages. These cells have a major role in inducing immunological responses. Both $\mathrm{B}$ and $\mathrm{T}$ lymphocytes have membrane-bound albumin as a "hidden" component, since the functional role(s) of the membrane albumin is unknown and because the protein is radiolabeled within the plasma membrane, but not from the cell exterior [23].

We have previously reported a decrease in albumin levels and a concomitant increase in oxidative stress in PBMC of STZ-induced diabetic rats [13]. Here, we expanded the previous study and investigated the effect of selenium (Se) supplementation on the levels of membrane-bound albumin and the production of ROS in PBMC of STZ-induced diabetic mice.

\section{MATERIALS AND METHODS}

Male ICR mice ( 8 weeks old) were obtained from Samtako Bio Korea (Osan, South Korea) and used after one week of quarantine and acclimation. Sodium selenate and seleno-L-methionine as Se source were purchased from Sigma-Aldrich (St. Louis, MO, U.S.A.). The Amplex ${ }^{\circledR}$ Red assay kit containing horseradish peroxidase and standard $\mathrm{H}_{2} \mathrm{O}_{2}$ solution was acquired from Invitrogen (Carlsbad, CA, U.S.A.). Monoclonal antibody against albumin was obtained from Santa Cruz Biotechnology (Santa Cruz, CA, U.S.A.). All equipment and buffer solutions for 2D-PAGE were purchased from GE Healthcare Biosciences (Piscataway, NJ, U.S.A.). 
Experimental animals: The mice were housed in stainless steel cages in a room at a controlled temperature of $24 \pm 1^{\circ} \mathrm{C}$ and lighting (alternating $12 \mathrm{hr}$ period of light and dark). All mice were fed distilled water and AIN-76A purified rodent diet (TestDiet, St. Louis, MO, U.S.A.), which was notified as Se-free diet by the manufacturer. Before sacrifice for blood collection, all mice were provided with food and water ad libitum. The experimental design was approved by the committee for the Care and Use of Laboratory Animals at the Chonnam National University.

Induction of DM and Se supplementation: The mice were divided into three groups (10 mice per each group), normal (Control), STZ-treated (STZ) and STZ plus Se-treated $(\mathrm{STZ}+\mathrm{Se})$. Before the STZ treatment, sodium selenate ( $0.2 \mathrm{mg} / \mathrm{kg}$ body weight) was administrated orally to mice once a day for two weeks. However, control and STZmice were not pretreated with any material. Then, diabetes was induced by a single intraperitoneal injection of STZ (40 mg/100 g body weight in $0.1 \mathrm{M}$ citrate buffer). Control mice were injected with the same volume of $0.1 \mathrm{M}$ citrate buffer only. The severity of the induced diabetic state was assessed by daily monitoring of blood glucose levels using reagent strips (ACCUTREND, Roche Diagnostics GmbH, Mannheim, Germany). Mice with blood glucose levels exceeding $300 \mathrm{mg} / \mathrm{d} l$ were classified as diabetic mice. Three weeks after STZ-injection, three groups of mice (Control, STZ and STZ+Se) were sacrificed. In case of STZ+Se group, Se was also supplemented during that time at the same dosage and via the same administration route described above. Each mouse's blood was collected from the caudal vena cava.

Blood biochemistry: Blood samples from the caudal vena cava were centrifuged to obtain hemolysis-free clear serum. The levels of blood urea nitrogen (BUN), creatinine (CRE), glucose (GLU), total cholesterol (T-CHO), total bilirubin (T-BIL), total protein (TP), albumin (ALB) and triglyceride (TG) were assayed using an autoanalyzer (Dir-chem 4000i, Fujifilm, Tokyo, Japan) by standard methods.

Purification and counting of PBMCs: Peripheral blood mononuclear cells were prepared from whole blood by Ficoll-Paque PLUS (GE Healthcare Biosciences). Briefly, EDTA-treated blood was diluted to 1:1 with phosphate buffered saline (PBS) plus 2\% fetal bovine serum and layered onto Ficoll-Paque PLUS with the ratio of blood plus PBS:Ficoll maintained at 2:1. The sample was then centrifuged at $400 \times g$ for $40 \mathrm{~min}$ at $25^{\circ} \mathrm{C}$. The buffy coat layer was removed and washed as follows: the cells were suspended in a balanced salt solution provided by the manufacturer, and the sample was then centrifuged at $100 \times \mathrm{g}$ for $10 \mathrm{~min}$ at $25^{\circ} \mathrm{C}$. The pellet was collected after removal of supernatant, and the washing step was repeated twice to remove any contaminant. The isolation of PBMC was verified by a flow cytometry analysis using anti-pan B-cells antibody (clone number of 68-IB3, Santa Cruz Biotechnology). The viable concentrations of isolated PBMCs from blood samples of each group were measured by manual counting with trypan blue using a hemacytometer as described previously [26].

$2 D-P A G E$ and immunoblot analysis: The PBMC samples were suspended in lysis buffer (40 mM Tris- $\mathrm{HCl}$ ( $\mathrm{pH} 7.4), 8 \mathrm{M}$ urea and $0.4 \% 3$ [(3-cholamidopropyl) dimethylammonio]propanesulfonic acid). For isoelectric focusing (IEF), $150 \mu \mathrm{g}$ proteins were diluted with the rehydration solution (GE Healthcare Biosciences), and the 7-cm immobilized $\mathrm{pH}$ gradient (IPG, pH 3-10) dry-strips were then overlaid onto the sample. After IEF, the individual strips were incubated at room temperature in equilibrium solution A $(50 \mathrm{mM}$ Tris- $\mathrm{HCl}$ (pH 8.8), $6 \mathrm{M}$ urea, 30\% (v/v) glycerol, 2\% SDS, bromophenol blue trace and $20 \mathrm{mM}$ DTT), followed by incubation in solution B (solution A except that DTT was replaced by $20 \mathrm{mM}$ iodoacetamide), for $15 \mathrm{~min}$ each. The IPG strips were then electrophoresed by $11 \%$ SDS-PAGE. The separated extracts of PBMC were transferred onto nitrocellulose membranes with $0.2 \mu \mathrm{m}$ pore size (Whatman, Maidstone, U.K.). The membrane was incubated overnight with monoclonal antibody against albumin at $4^{\circ} \mathrm{C}$ and then anti-mouse $\mathrm{IgG}$ conjugated with peroxidase (Sigma-Aldrich) for $1 \mathrm{hr}$ at room temperature. The Enhanced chemiluminescence kit (GE Healthcare Biosciences) was used to detect albumin.

Quantitative real-time PCR ( $q R T-P C R)$ : Total RNA was extracted from intact PBMC $\left(\sim 2.7 \times 10^{6}\right.$ cells $)$ by using the RNeasy Mini Kit (Quiagen, Hilden, Germany). The extracted RNA was subjected to first-strand cDNA synthesis using the Reverse Transcription System (Promega, Madison, WI, U.S.A.) according to the manufacturer's protocol. qRT-PCR was performed using Rotor-Gene 6000 (Quiagen), and the $2^{-\Delta \Delta \mathrm{C}} \mathrm{T}$ method was used for relative quantitation. Threshold cycle number and reaction efficiency were determined using Rotor-Gene 6000 series software version 2.7. The DNA sequences for albumin and GAPDH primers were the same with those as described previously [13]

Measurement of ROS: The amount of $\mathrm{H}_{2} \mathrm{O}_{2}$ generated was measured spectrofluorimetrically using the Amplex ${ }^{\circledR}$ Red (AR) assay kit according to the manufacturer's instructions. Fluorescence was recorded by the AR assay at an emission wavelength of $585 \mathrm{~nm}$ and an excitation wavelength of $571 \mathrm{~nm}$. Lipid peroxidation (LPO) was estimated by measuring thiobarbituric acid-reactive substances, by using malondialdehyde as a standard, as described previously [11]. Reduced glutathione (GSH) levels were determined by the sulfhydryl content using Ellman's reagent [3]. The ratio of GSH/GSSG (oxidized glutathione) was also determined by a GSH/GSSG ratio assay kit (Abcam, Cambridge, MA, U.S.A.). The amounts of $\mathrm{H}_{2} \mathrm{O}_{2}$ and $\mathrm{GSH}$ were measured with cytosolic fractions of PBMC. LPO was estimated with microsomal fractions of PBMC.

Statistical analysis: Data are expressed as mean \pm S.E. of ten animals per group. Statistical analyses were performed using Student's $t$-test for two groups. A $P$-value $<0.05$ was considered significant.

\section{RESULTS}

Blood biochemistry: We analyzed 9 biochemical parameters of blood serum to validate STZ-induced DM and investigate Se effect on the possible changes in the param- 
Table 1. Serum biochemical parameters of normal (Control), STZ and STZ+Se mice

\begin{tabular}{|c|c|c|c|c|c|}
\hline & $\operatorname{ALB}(\mathrm{g} / \mathrm{d} l)$ & $\mathrm{TP}(\mathrm{g} / \mathrm{d} l)$ & $\mathrm{BUN}(\mathrm{mg} / \mathrm{d} l)$ & $\mathrm{GLU}(\mathrm{mg} / \mathrm{d} l)$ & CRE (mg/d $l$ ) \\
\hline Control & $2.7 \pm 0.2$ & $4.5 \pm 0.4$ & $15.1 \pm 2.4$ & $115.4 \pm 20.7$ & $0.3 \pm 0.1$ \\
\hline STZ & $2.1 \pm 0.1^{\mathrm{a})}$ & $3.2 \pm 0.2^{\mathrm{a})}$ & $35.4 \pm 7.5^{\mathrm{a})}$ & $483.2 \pm 38.5^{\mathrm{a})}$ & $0.3 \pm 0.1$ \\
\hline $\mathrm{STZ}+\mathrm{Se}$ & $2.2 \pm 0.2^{\mathrm{a})}$ & $3.3 \pm 0.2^{\mathrm{a})}$ & $\left.22.8 \pm 3.5^{\mathrm{a}, \mathrm{b}}\right)$ & $\left.245.3 \pm 30.2^{\mathrm{a}, \mathrm{b}}\right)$ & $0.3 \pm 0.2$ \\
\hline & $\mathrm{T}-\mathrm{CHO}(\mathrm{mg} / \mathrm{d} l)$ & T-BIL $(\mathrm{mg} / \mathrm{d} l)$ & $\mathrm{TG}(\mathrm{mg} / \mathrm{d} l)$ & BUN/CRE & \\
\hline Control & $94.7 \pm 18.2$ & $0.3 \pm 0.1$ & $109.2 \pm 23.1$ & $46.3 \pm 7.5$ & \\
\hline STZ & $85.5 \pm 14.6$ & $0.6 \pm 0.2^{\mathrm{a})}$ & $220.8 \pm 59.4^{\mathrm{a})}$ & $124.4 \pm 15.2^{\mathrm{a})}$ & \\
\hline $\mathrm{STZ}+\mathrm{Se}$ & $89.8 \pm 20.1$ & $0.5 \pm 0.2$ & $152.8 \pm 25.7^{\mathrm{a}, \mathrm{b})}$ & $72.1 \pm 9.3^{\mathrm{a}, \mathrm{b})}$ & \\
\hline
\end{tabular}

Data are mean \pm S.E., $\mathrm{n}=10$ (per each group), a) $P<0.05$ vs control, b) $P<0.05$ vs. STZ.

eters. Table 1 shows the elevated levels of TG and GLU as well as decreased TP and ALB contents in STZ-treated mice compared with those of normal group (control), which are the common characteristic features of diabetes. In addition to these values, BUN/CRE ratio in STZ-treated mice was approximately 2.7 -fold higher than that of normal mice. However, CRE, T-CHO and T-BIL values showed marginal differences between the two groups. These changes are in agreement with our previous results using diabetic rats [13]. When the blood samples of Se supplementation group were analyzed, Se decreased the STZ-induced elevation in TG level and BUN/CRE ratio with statistical significance. In particular, the increased GLU value by STZ injection (approximately $400 \mathrm{mg} / \mathrm{d} l$ ) was gradually attenuated during three weeks in STZ+Se group, and the level reached about $245 \mathrm{mg} / \mathrm{d} l$ (Fig. 1). On the contrary, other parameters did not show any notable change. The body weights of STZmice were lower than those for normal group; however, Se supplementation could not recover the body weight with statistical significance (results not shown).

PBMC-albumin levels: Using 2-D PAGE and immunoblotting with anti-albumin antibody, albumin contents in PBMC were analyzed in normal, STZ and STZ+Se mice. As shown in Fig. 2A, PBMC-albumin content was significantly reduced in STZ mice compared to that of normal group, although quantitative measurements were not performed with the spot observed in immunoblotting. The albumin levels of PBMC in STZ+Se mice were similar to those of control group. As a control experiment, the albumin spots were picked from the gels and were then analyzed by MALDI-TOF mass spectroscopy to verify the protein spots as albumin as described previously [13] (result not shown). In addition, all samples in STZ or STZ+Se consistently showed decreased or restored albumin content in 2D-PAGE and immunoblot analysis, although the expression levels were different among samples and exact quantification could not be performed.

To confirm the results obtained by immunoblotting, the changes in the levels of PBMC-albumin were evaluated at RNA level using qRT-PCR (Fig. 2B); RNA transcription decreased in diabetic PBMC by about $90 \%$ compared with that of the normal group. However, consistent with the immunoblotting results, the RNA levels reached approximately $85 \%$ of normal mice in Se-treated diabetic group. This result strongly indicates that $\mathrm{Se}$ supplementation recovers the

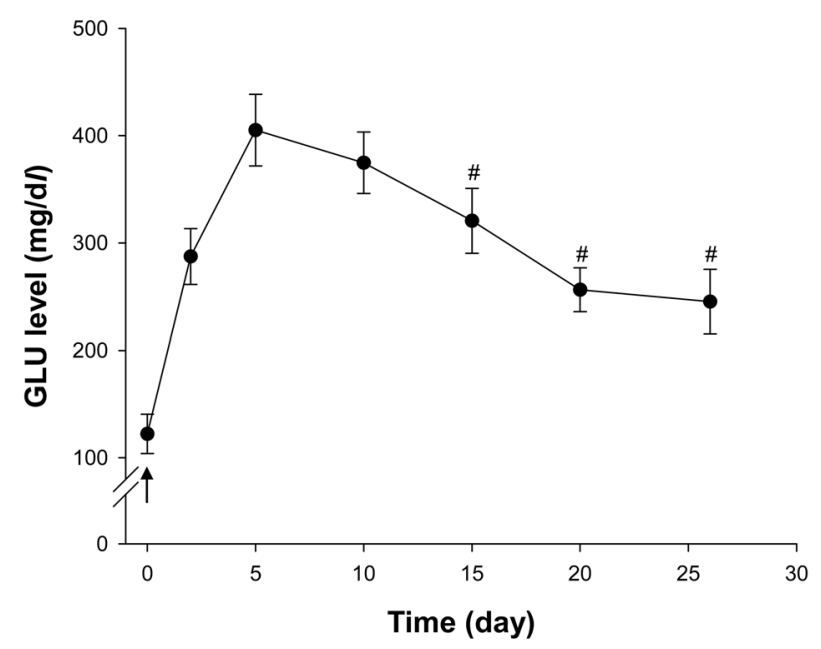

Fig. 1. Time-dependent decrease in GLU level by Se supplementation. After STZ injection, GLU concentrations of blood samples were measured at each indicated time during three weeks in STZ+Se group. An arrow represents a STZ injection, and the value at time zero (0) indicates the average GLU concentration of nondiabetic mice. Statistical symbols were marked for GLU values after STZ treatment. \#, $P<0.05$ vs the maximum GLU value, $\mathrm{n}=10$ (per each point).

decreased expression of albumin in PBMC, although there is no experimental evidence(s) how Se influences on the albumin expression at present. Taken together, these results suggest that Se alleviates STZ-induced repression of albumin expression in PBMC of mice.

When the experiments were repeated with seleno-L-methionine $(0.5 \mathrm{mg} / \mathrm{kg}$ body weight administered in a similar manner as selenate), the albumin levels in PBMC showed moderate recovery (results not shown). These results suggest that inorganic Se is more effective in modulating the expression of PBMC-albumin than organic Se, which is different to the previous report that seleno-L-methionine is more prominent than selenate in increasing antioxidant enzyme activity, such as glutathione peroxidase [5]. However, other organic forms of Se including higher dosage were not investigated, and the precise mechanism(s) and reason(s) are not clearly understood. 
A

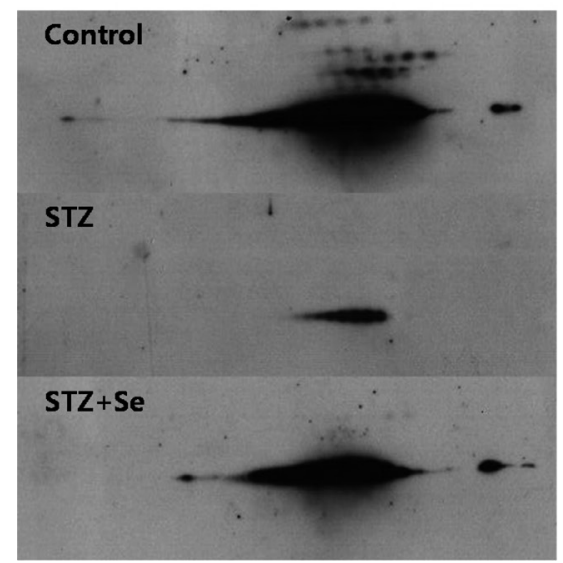

B

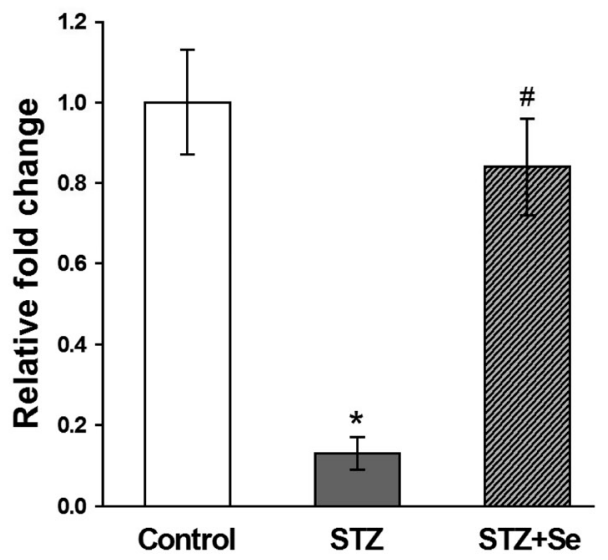

Fig. 2. 2D-PAGE/Immunoblot (A) and qRT-PCR (B) analyses with PBMC proteins and RNAs, respectively. (A) Protein extracts (total amount of $150 \mu \mathrm{g}$ ) from the PBMCs of normal (Control), STZ and STZ+Se mice were separated by 2D-PAGE, and immunoblot was performed with anti-albumin antibody. The ECL kit was used to visualize the protein spots. (B) The transcriptional level of the albumin gene was measured by qRT-PCR and expressed as relative fold change after quantitation of cDNA. The transcription level of normal PBMC was normalized to be one (1) in the figure. *, $P<0.05$ vs control; \#, $P<0.05$ vs. STZ, n=10 (per each group).

Table 2. Measurement of oxidative stress in PBMC samples and relative PBMC concentrations of normal (Control), STZ and STZ+Se mice

\begin{tabular}{lccccc}
\hline & $\begin{array}{c}\mathrm{H}_{2} \mathrm{O}_{2} \\
(\mathrm{pmol} / \mathrm{mg} \text { protein })\end{array}$ & $\begin{array}{c}\mathrm{LPO} \\
(\mathrm{nmol} / \mathrm{mg} \text { protein })\end{array}$ & $\begin{array}{c}\mathrm{GSH} \\
(\mathrm{nmol} / \mathrm{min} / \mathrm{mg} \text { protein })\end{array}$ & $\begin{array}{c}\text { GSH/GSSG } \\
\text { ratio }\end{array}$ & $\begin{array}{c}\text { PBMC } \\
\text { concentration }\end{array}$ \\
\hline Control & $5.4 \pm 2.8$ & $4.8 \pm 2.3$ & $46.2 \pm 8.9$ & $1.32 \pm 0.38$ & 1 \\
$\mathrm{STZ}$ & $14.6 \pm 4.5^{\mathrm{a})}$ & $16.3 \pm 3.7^{\mathrm{a})}$ & $21.7 \pm 5.2^{\mathrm{a})}$ & $0.51 \pm 0.22^{\mathrm{a})}$ & $0.79 \pm 0.13^{\mathrm{a})}$ \\
$\mathrm{STZ}+\mathrm{Se}$ & $6.3 \pm 2.2^{\mathrm{b})}$ & $5.7 \pm 2.1^{\mathrm{b})}$ & $38.4 \pm 8.3^{\mathrm{b})}$ & $0.98 \pm 0.17^{\mathrm{b})}$ & $0.92 \pm 0.14$ \\
\hline
\end{tabular}

Data are mean \pm S.E., $\mathrm{n}=10$ (per each group), a) $P<0.05$ vs control, b) $P<0.05$ vs STZ.

ROS production in PBMC and PBMC concentrations: To examine the correlation between the changes in albumin expression levels and oxidative stress, the generation of $\mathrm{H}_{2} \mathrm{O}_{2}$ and LPO was measured in normal, STZ and STZ+Se PBMC. Table 2 shows that $\mathrm{H}_{2} \mathrm{O}_{2}$ and LPO levels were significantly enhanced by approximately 2.7- and 3.4-fold, respectively, in diabetic PBMC compared with those of the control sample. In parallel with the elevated production of $\mathrm{H}_{2} \mathrm{O}_{2}$ and LPO, GSH content was $47 \%$ of the control value in STZ sample. The ratio of GSH/GSSG, a useful indicator of oxidative stress, was also determined. Normal mice showed a ratio of 1.32 , implying that the concentration of reduced glutathione is higher than that of the oxidized form. In parallel with other ROS parameters, the ratio decreased to 0.51 in diabetic PBMC, suggesting the induction of an increased oxidative state by STZ. However, Se supplementation recovered most of the STZ-induced oxidative defects up to the levels of normal mice.

To correlate the decreased or the increased ROS production with PBMC viability and integrity, PBMC concentration was also measured with normal, STZ and STZ+Se groups. Table 2 indicates that PBMC concentration was relatively reduced by about $20 \%$ in STZ mice compared to normal mice when the value for control group set to one (1). Regarding the results for oxidative stress, it could be speculated that the stimulation of ROS production in STZ mice may be responsible for the reduced PBMC numbers, although other reasons could also be involved. On the contrary, Se supplementation recovered the reduction up to that observed for normal mice, suggesting the protective effect of Se against STZ-induced PBMC damages.

\section{DISCUSSION}

Se is a trace nutritional element and is known to exert many biological functions in immunity regulation, health and productivity in mammals including humans [27]. However, it is still controversial whether Se is beneficial or detrimental in human and animal health, and it is considered to have the both faces at present $[12,17]$. This consideration is also applied to diabetes, and there are conflicting studies regarding relationship between Se and the prevalence of diabetes, especially type $2[18,29]$. In accordance with these studies, it was recently suggested that Se acts as a "double-edged sword" in diabetes [25]. In this paper, dietary selenate supplementation decreased hyperglycemia by increasing insulin production in 
$d b / d b$ mice. However, long-term ( 9 weeks) intake of selenate induced fatty liver degeneration by inducing the hyperinsulinemia and reducing anti-oxidant capacity.

To reinvestigate and validate the Se effect on the type $1 \mathrm{DM}$, we first analyzed the blood samples for STZ and STZ+Se mice and compared the parameters with those of normal group (Table 1). Se supplementation decreased the elevated levels of TG, GLU and BUN/CRE ratio of STZmice. The BUN/CRE ratio is considered a useful index to evaluate renal insufficiency [8]. It has also been suggested that acute renal insufficiency, which is developed in STZinduced DM, causes an increase in the BUN/CRE ratio [20]. These results were similar to those of a recent study, which suggested that long-term supplementation of selenate decreases glucose and triglyceride levels in the plasma of diabetic $d b / d b$ mice [25]. On the basis of these results, it was suggested that Se supplementation may be in part effective to alleviate pathological defects of serum caused by type 1 DM in mice, although Se-induced changes in parameters did not reach the values for normal (control) mice.

Based on our previous results [13], we investigated the direct relation between protein levels in PBMC and STZ (also STZ+Se) treatment. The results obtained from 2DPAGE/immunoblotting and qRT-PCR experiments (Fig. 2) were somewhat different from those of the previous study using rats as an animal model, which STZ treatment almost repressed the phenotypic expression of albumin in mice. Therefore, it might be suggested that PBMC-albumin expression of mice is more vulnerable to STZ and/or STZ-induced biological defects than that of rats. However, Se supplementation restored the STZ-induced repression of the albumin expression up to the levels of normal mice. In parallel with the repression and the restoration of PBMC-albumin expression, the production of oxidative stresses in the cells showed similar patterns. The previous report has suggested that excessive ROS production can attack cellular components of lymphocytes leading to damage and malfunction of the cells [15]. Therefore, these results suggest that the decreased expression of albumin could be one of the reasons resulting in enhanced oxidative stress in PBMC of mice and that Se intake represses the production of ROS and thereby protects the cells against oxidative damages. However, a direct correlation between PBMC-albumin and oxidative stresses has not been confirmed by other research groups. The functional role of PBMC-albumin should be further investigated.

As suggested previously, STZ induced the repressed expression of albumin and stimulated the production of oxidative stresses in PBMC of rats [13]. In relation with Se and diabetes, it was suggested that while Se deficiency resulted in renal oxidative stress, Se supplementation to diabetic rats prevented the production of oxidative stress and renal structural injury [19]. The effects of Se intake have been evaluated with two factors, $\mathrm{Se}$ as an insulinmimetic and ROS-related protein expression induced by Se: inorganic Se, such as sodium selenate, stimulated glucose uptake in rat adipocytes suggesting insulin-like effect of Se [6]. Moreover, sodium selenate and seleno-L-methionine showed insulin-like and anti-diabetic effects in STZ-induced diabetic mice and rats $[5,28]$. All these results, therefore, indicate that Se acted as an insulin-mimic and exerts positive effects on glucose homeostasis. Regarding protein expression, it has been suggested that Se intake elevated activity or production of seleno-proteins including glutathione peroxidase 1, methionine-R-sulfoxide reductase 1, selenoprotein $\mathrm{S}$ and selenoprotein $\mathrm{P}$, which diminished the production of intracellular ROS [29].

In conclusion, we suggest that Se supplementation protects PBMC of mice from STZ-induced detrimental effects, such as suppression of PBMC-albumin expression, increase in oxidative stresses and decrease in PBMC concentration, as well as hyperglycemia and other defects in blood parameters. As describe above, moderate recovery of the albumin repression was also observed when seleno-L-methionine as a Se source was administered to mice instead of inorganic Se, although the effect of organic Se was lower than inorganic Se and these studies were primitive. Therefore, these investigations suggest the anti-diabetic effects of Se at least in PBMC of STZ-diabetic mice regardless of the Se form administered. However, further studies should be also performed to improve experimental conditions, such as optimum or minimum-required Se dosage, duration time of Se treatment before or after DM induction and optimum administration route to exert the anti-diabetic effects of Se.

ACKNOWLEDGMENT. This research was supported by the Next-Generation BioGreen 21 program (SSAC grant\# PJ011058), Rural Development Administration, Republic of Korea.

\section{REFERENCES}

1. Baynes, J. W. and Thorpe, S. R. 1999. Role of oxidative stress in diabetic complications: a new perspective on an old paradigm. Diabetes 48: 1-9. [Medline] [CrossRef]

2. Bourdon, E. and Blache, D. 2001. The importance of proteins in defense against oxidation. Antioxid. Redox Signal. 3: 293-311. [Medline] [CrossRef]

3. Buttar, H. S., Chow, A. Y. K. and Downie, R. H. 1977. Glutathione alterations in rat liver after acute and subacute oral administration of paracetamol. Clin. Exp. Pharmacol. Physiol. 4: 1-6. [Medline] [CrossRef]

4. Desco, M. C., Asensi, M., Márquez, R., Martínez-Valls, J., Vento, M., Pallardó, F. V., Sastre, J. and Viña, J. 2002. Xanthine oxidase is involved in free radical production in type 1 diabetes: protection by allopurinol. Diabetes 51: 1118-1124. [Medline] [CrossRef]

5. Erbayraktar, Z., Yilmaz, O., Artmann, A. T., Cehreli, R. and Coker, C. 2007. Effects of selenium supplementation on antioxidant defense and glucose homeostasis in experimental diabetes mellitus. Biol. Trace Elem. Res. 118: 217-226. [Medline] [CrossRef]

6. Ezaki, O. 1990. The insulin-like effects of selenate in rat adipocytes. J. Biol. Chem. 265: 1124-1128. [Medline]

7. Hunt, J. V., Dean, R. T. and Wolff, S. P. 1988. Hydroxyl radical production and autoxidative glycosylation. Glucose autoxidation as the cause of protein damage in the experimental glycation model of diabetes mellitus and ageing. Biochem. J. 256: 205-212. [Medline] [CrossRef] 
8. Kouki, T., Komiya, I. and Masuzaki, H. 2010. The ratio of the blood urea nitrogen/creatinine index in patients with acute renal failure is decreased due to dextran or mannitol. Intern. Med. 49: 223-226. [Medline] [CrossRef]

9. Low, P. A., Nickander, K. K. and Tritschler, H. J. 1997. The roles of oxidative stress and antioxidant treatment in experimental diabetic neuropathy. Diabetes 46 Suppl 2: S38-S42. [Medline] [CrossRef]

10. Nahon, J. L., Tratner, I., Poliard, A., Presse, F., Poiret, M., Gal, A., Sala-Trepat, J. M., Legrès, L., Feldmann, G. and Bernuau, D. 1988. Albumin and $\alpha$-fetoprotein gene expression in various nonhepatic rat tissues. J. Biol. Chem. 263: 11436-11442. [Medline]

11. Ohkawa, H., Ohishi, N. and Yagi, K. 1979. Assay for lipid peroxides in animal tissues by thiobarbituric acid reaction. Anal. Biochem. 95: 351-358. [Medline] [CrossRef]

12. Oldfield, J. E. 1987. The two faces of selenium. J. Nutr. 117: 2002-2008. [Medline]

13. Park, K. T., Yun, C. H., Bae, C. S. and Ahn, T. 2014. Decreased level of albumin in peripheral blood mononuclear cells of streptozotocin-induced diabetic rats. J. Vet. Med. Sci. 76: 1087-1092. [Medline] [CrossRef]

14. Peavy, D. E., Taylor, J. M. and Jefferson, L. S. 1985. Time course of changes in albumin synthesis and mRNA in diabetic and insulin-treated diabetic rats. Am. J. Physiol. 248: E656-E663. [Medline]

15. Perez de Castro, I., Bivona, T. G., Philips, M. R. and Pellicer, A. 2004. Ras activation in Jurkat $\mathrm{T}$ cells following low-grade stimulation of the T-cell receptor is specific to N-Ras and occurs only on the Golgi apparatus. Mol. Cell. Biol. 24: 3485-3496. [Medline] [CrossRef]

16. Peters, T. Jr. 1977. Serum albumin: recent progress in the understanding of its structure and biosynthesis. Clin. Chem. 23: 5-12. [Medline]

17. Rayman, M. P. 2012. Selenium and human health. Lancet 379: 1256-1268. [Medline] [CrossRef]

18. Rayman, M. P. and Stranges, S. 2013. Epidemiology of selenium and type 2 diabetes: can we make sense of it? Free Radic. Biol. Med. 65: 1557-1564. [Medline] [CrossRef]
19. Reddi, A. S. and Bollineni, J. S. 2001. Selenium-deficient diet induces renal oxidative stress and injury via TGF- $\beta 1$ in normal and diabetic rats. Kidney Int. 59: 1342-1353. [Medline] [CrossRef]

20. Reynolds, R. M., Padfield, P. L. and Seckl, J. R. 2006. Disorders of sodium balance. BMJ 332: 702-705. [Medline] [CrossRef]

21. Roche, M., Rondeau, P., Singh, N. R., Tarnus, E. and Bourdon, E. 2008. The antioxidant properties of serum albumin. FEBS Lett. 582: 1783-1787. [Medline] [CrossRef]

22. Shamay, A., Homans, R., Fuerman, Y., Levin, I., Barash, H., Silanikove, N. and Mabjeesh, S. J. 2005. Expression of albumin in nonhepatic tissues and its synthesis by the bovine mammary gland. J. Dairy Sci. 88: 569-576. [Medline] [CrossRef]

23. Sidman, C. L. 1981. Lymphocyte surface receptors and albumin. J. Immunol. 127: 1454-1458. [Medline]

24. Vincent, A. M., Brownlee, M. and Russell, J. W. 2002. Oxidative stress and programmed cell death in diabetic neuropathy. Ann. $N$. Y. Acad. Sci. 959: 368-383. [Medline] [CrossRef]

25. Wang, C., Yang, S., Zhang, N., Mu, Y., Ren, H., Wang, Y. and Li, K. 2014. Long-term supranutritional supplementation with selenate decreases hyperglycemia and promotes fatty liver degeneration by inducing hyperinsulinemia in diabetic $d b / d b$ mice. PLoS ONE 9: e101315. [Medline] [CrossRef]

26. Weinberg, A., Zhang, L., Brown, D., Erice, A., Polsky, B., Hirsch, M. S., Owens, S. and Lamb, K. 2000. Viability and functional activity of cryopreserved mononuclear cells. Clin. Diagn. Lab. Immunol. 7: 714-716. [Medline]

27. Yoon, I., Werner, T. M. and Butler, J. M. 2007. Effect of source and concentration of selenium on growth performance and selenium retention in broiler chickens. Poult. Sci. 86: 727-730. [Medline] [CrossRef]

28. Zeng, J., Zhou, J. and Huang, K. 2009. Effect of selenium on pancreatic proinflammatory cytokines in streptozotocin-induced diabetic mice. J. Nutr. Biochem. 20: 530-536. [Medline] [CrossRef]

29. Zhou, J., Huang, K. and Lei, X. G. 2013. Selenium and diabetes-evidence from animal studies. Free Radic. Biol. Med. $\mathbf{6 5}$ 1548-1556. [Medline] [CrossRef] 